\title{
1. Introduction: occupational health and safety in small and medium sized enterprises
}

\author{
E. Kevin Kelloway and Cary L. Cooper
}

Although small and medium sized enterprises play a vital role in the economy, issues of occupational health and safety are often ignored in such organizations. Researchers in occupational health and safety, as in other areas of organizational research, typically focus on large businesses where it is relatively easy to obtain large sample sizes. Interventions (e.g. inspections, training) to enhance occupational health and safety often require resources or expertise that are not readily available in smaller businesses and may, in fact, be inappropriate for small business (MacEachen et al., 2008). Moreover, the small business sector is characterized by financial fragility and instability, making it difficult to enforce occupational health and safety standards in this environment. Indeed occupational health and safety regulations may specifically exempt small businesses from particular provisions. For example, in Canada, joint managementlabour occupational health and safety committees are required in virtually every occupational health and safety act but only for businesses with at least 20 employees - a provision that exempts most small businesses from the requirement.

As a result of these characteristics, issues of occupational health and safety assume particular importance in a small business. Workplace fatalities are higher in industries characterized by a large number of small businesses (Lentz and Wenzl, 2006; National Institute for Occupational Safety and Health, 1999) and the solutions that are enshrined in contemporary occupational health and safety programming may be ineffective or irrelevant in the small business environment.

Defining the term 'small business' is actually more difficult than it first appears. Official agencies might cite definitions such as businesses employing less than 100 employees (or less than 50 employees for service organizations; see e.g. http://www.ic.gc.ca/epic/site/sbrp-rppe.nsf/en/rd01225e. html), however the reality is that the vast majority of small business is, 
in fact, micro business. In Canada, 75 per cent of all businesses employ fewer than five people and 97 per cent of all businesses employ less than 50 employees (Debus, 2005). In the European Union, 99 per cent of all enterprises are small businesses employing less than 50 people and over 90 per cent are micro-businesses employing less than 10 people (European Commission, 2004). Thirty-two per cent of all employees in Canada (Debus, 2005) and just under 57 per cent of employees in the European Union (European Commission, 2004) are employed in a small business (i.e. less than 20 employees).

\section{THE NATURE OF THE PROBLEM}

These statistical observations provide the basis for defining the domain of small businesses. However, the implications of size for the implementation of occupational health and safety procedures and programmes requires further explication. When it comes to issues related to human resources, including occupational health and safety, small businesses have no knowledge, no time, and no resources. The lack of knowledge stems from the absence of any professionalized human resource functions - for the most part, the business owner is the human resource department (and every other department of the business). Only in extraordinarily rare cases will the owner have specialized knowledge related to management of occupational health and safety. Second, the multiplicity of roles and the small workforce means that small business owners have no time - programmes that require substantial commitments of time or attempts to educate or inform small business owners through seminars, workshops and other activities that will take them away from their business are likely to have minimal impact. Finally, small business owners have limited resources they certainly are unlikely to hire consultants to solve problems and will never have the resources to solve problems through experimentation or pilot studies.

These concerns are not unique to occupational health and safety - in general small businesses tend to operate without formal work procedures (Aragon et al., 2001; Walters, 1998) and without administrative support (Eakin et al., 2003). In her study of small business owners, Eakin (1992; see also Niewohner et al., 2004) reported that they also did not see occupational health and safety as being within their responsibility. Rather, owners saw issues of health and safety as either 'bureaucratic' concerns or issues of personal responsibility for their employees.

Responsibility for occupational health and safety is further obscured by subcontracting practices endemic among small businesses (e.g. in 
construction). As a result of these practices the nature of employment relationships (e.g. who is the employer) becomes unclear, as does responsibility for establishing and maintaining occupational health and safety systems (Mayhew and Quinlan, 1997). Within this environment, a strong culture of autonomy and meeting the demands of contracts supersede detailed consideration of occupational health and safety issues.

\section{IDENTIFYING BEST PRACTICES: THE CURRENT VOLUME}

Given the characteristics of small businesses described above, it is not surprising to note that research on occupational health and safety in small business is lacking. In their systematic review of health and safety interventions, MacEachen et al. (2008) were able to identify only five high quality quantitative studies and 14 qualitative studies conducted in small businesses. Not surprisingly, research designs tended to be sub-optimal with a lack of control groups and appropriate comparisons.

A moment's consideration points to the difficulties of conducting research in a small business environment. The size of the business often precludes setting up 'experimental' and 'control' conditions within a single organization. The culture of small business and the exigencies of business survival do not support the conduct of research. Logistical difficulties in planning research (i.e. the difficulties of negotiating entry and obtaining the buy-in of business owners) are magnified in small businesses. In contrast to negotiating entry into one large organization, researchers may have to negotiate entry into 20 or 30 small businesses to obtain an equivalent sample. Organizational differences then become an additional analytic challenge as data from multiple small businesses have a nested hierarchical structure that precludes the use of some common methods of statistical analysis.

With this volume we hope to advance research on occupational health and safety in small and medium sized enterprises. We have recruited authors with a great deal of expertise and asked them to focus on the nature of occupational health and safety in small and medium sized enterprises, summarizing existing knowledge and research.

We also asked authors to go beyond traditional research reviews. Specifically, we asked individuals to go beyond summarizing the research results to consider the nature of small and medium sized enterprises and how occupational health and safety might be enhanced in these organizations. In each case, authors have attempted to identify 'workable' and likely to be effective solutions to enhance occupational health 
and safety in small and medium sized enterprises. There is considerable agreement among authors that the greatest potential for enhancing occupational health and safety is to capitalize on the informal nature of work in small and medium sized enterprises - focusing on enhancing flexibility and informal communications in the organization.

\section{OUTLINE OF THIS VOLUME}

In general the book begins with a consideration of issues germane to 'safety' in organizations and moves to a consideration of issues more related to health and, in particular, psychosocial influences on health. However, the dividing line between 'safety' and 'health' is, at best, an arbitrary distinction.

In the initial chapter, Sharon Clarke provides an overview of occupational health and safety issues in small and medium sized enterprises. Based on her consideration of the issues, she points to the fallacy of believing that effective occupational health and safety solutions can simply be 'scaled down' versions of what works in larger enterprises. Rather, she argues that interventions based on enhancing safety culture are most likely to have a positive effect on occupational health and safety in small and medium sized enterprises.

Small businesses predominate in some sectors and Fleming and Scott report on a study examining the practices of small businesses within the construction sector. Their innovative study contrasted the differences between small businesses with 'low' and 'high' accident statistics. They identify both formal safety procedures and informal practices that differentiate the two types of companies and, in doing so, point the way to effective health and safety programming in this environment.

Kelloway and Teed consider issues of workplace violence in small and medium sized enterprises. They begin by focusing on the observation that workplace violence is typically perpetrated by members of the public or by clients rather than by co-workers or fellow employees. Small and medium sized businesses are predominant in the service and retail sectors in which employees are most likely to be exposed to the risk factors for workplace violence.

Chen and Stallones focus on issues of occupational health and safety in the agricultural industry. Although many of the hazards of agricultural work are well known (e.g. the dangers of working with heavy equipment, exposure to toxic chemicals, etc.), Chen and Stallones highlight what they refer to as the 'hidden' hazard - self-inflicted injury. In doing so they focus 
on the psychosocial aspects of agricultural work and issues of occupational culture that may lead to these issues being hidden.

Johnson offers a broader conceptualization of psychosocial issues by reviewing issues of stress and stress management in small and medium sized enterprises. She identifies the impact that stress-related issues have on work-related outcomes (e.g. absenteeism) and, by extension, on the viability of the business. After reviewing the state of knowledge regarding occupational stress she identifies specific practices and resources likely to help small businesses address these issues.

O'Driscoll, Brough and Haar, focus on a specific psychosocial stressor - work and family conflict in small businesses. Again, the focus is on the specific nature of small and medium sized enterprises and the identification of practices that are appropriate to, and likely to be effective for, small businesses.

In contrast to issues of work and family, which are widely recognized as requiring attention, issues of sexual harassment in small and medium sized enterprises have largely escaped research attention. Dionisi and Barling address this issue, arguing that there is no reason to expect that sexual harassment is less prevalent in small and medium sized enterprises than in larger businesses. Indeed, there may be some reasons to suspect that sexual harassment is more prevalent in small and medium sized enterprises. Dionisi and Barling also consider aspects of small business that may provide a 'protective' function and suggest interventions and strategies to deal with sexual harassment in small and medium sized enterprises.

The last chapter in the volume is authored by Day who considers the possibility of creating a psychologically healthy environment in small and medium sized enterprises. As in previous chapters, Day argues that the available data support the suggestions that (a) practices that 'work' in larger organizations may not readily generalize to small and medium sized enterprises, and (b) practices intended to be implemented in small businesses must take into account the nature of the small business environment.

We suggest that these themes run through each of the chapters in this volume. Those interested in promoting occupational health and safety in small and medium sized enterprises cannot expect that practices and procedures developed for large organizations will work in smaller organizations. The clear need is for low cost, low tech, non-resource demanding, interventions that can be readily deployed in a small business setting. Such interventions would capitalize on the culture and nature of small businesses and are likely to be effective in enhancing occupational health and safety in small and medium sized enterprises. 


\section{REFERENCES}

Aragon, A., Aragon, C. and Thorn, A. (2001), 'Pests, peasants and pesticides on the Northern Nicaraguan Pacific Plain', International Journal of Occupational and Environmental Health, 7, 295-302.

Debus, A. (2005), Small Business Profile: An Overview of Canada's Small and Mid-sized Business Sector, Ottawa, ON: Canadian Federation of Independent Business.

Eakin, J.M. (1992), 'Leaving it up to the workers: sociological perspectives on the management of health and safety in small workplaces', International Journal of Health Services, 22, 689-704.

Eakin, J.M., MacEachen, E. and Clarke, J. (2003), "'Playing it smart"” with return to work: small workplace experiences under Ontario's policy of self-reliance and early return', Policy and Practices in Health and Safety, 1, 19-41.

European Commission (2004), SMEs in Europe, 2003, Luxemburg: European Commission.

Lentz, T.J. and Wenzl, T.B. (2006), 'Small businesses with high fatality rates: assessment of hazards and their prevention', Journal of Occupational and Environmental Hygiene, 3, D8-D14.

MacEachen, E., Breslin, C., Kyle, N., Irvin, E., Kosny, A., Bigelow, P., Mahood, Q., Scott-Dixon, L., Morassaei, S., Facey, M., Chambers, L., Couban, R., Shannon, H., Cullen, K. and Amick, B. (2008), Effectiveness and Implementation of Health and Safety Programs in Small Enterprises: A Systematic Review of the Qualitative and Quantitative Literature, Toronto: Institute for Work and Health.

Mayhew, C. and Quinlan, M. (1997), 'Subcontracting and occupational health and safety in the residential building industry', Industrial Relations Journal, 28, 192.

National Institute for Occupational Safety and Health (NIOSH) (1999), Identifying High-risk Small Business Industries: The Basis for Preventing Occupational Injury, Illness and Fatality, Cincinatti, OH: NIOSH Special Hazard Review.

Niewohner, J., Cox, P., Gerrard, S. and Pidgeon, N. (2004), 'Evaluating the efficacy of a mental models approach for improving occupational chemical risk protection', Risk Analysis, 24, 349-361.

Walters, D. (1998), 'Employee representation on health and safety committees in small enterprises', Employee Relations, 20, 164-179. 